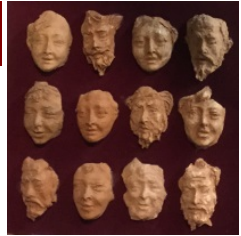

\title{
El Proyecto Nacional de Escritura y los Talleres de Escritura
}

\author{
Victoriano Garza-Almanza
}

@publicaoperece | publicaoperece.com | vgarza@uacj.mx

Los talleres de escritura, como elemento básico de la enseñanza formal, son la regla en todos los niveles de educación $\mathrm{K}-12$ de las escuelas de los Estados Unidos, y la regulación se aplica desde el kindergarten hasta el $12^{\circ}$ grado o preuniversitario.

¿A qué se debe esto? ¿Siempre fue así? ¿Qué acaso quieren convertir a todo el mundo en escritor? ¿Qué nos enseña? ¿Qué podemos aprender de esto?

La exigencia de la escritura (no confundir con alfabetización) como herramienta para la vida profesional, comenzó a instituirse a nivel superior -en prestigiosas universidades estadounidenses- desde el siglo XIX. En especial, para la preparación de ensayos, que se consideraban la base para la redacción de discursos, informes de trabajo, reportes de investigación, memorias de negocios, redacción de historias, documentación de actividades, etc.
Pero no había una enseñanza de la escritura en el aula, el estudiante tenía que aprender por sí mismo a escribir la clase de documentos que se le requerían en el momento, o que presuponía le iban a solicitar en los siguientes cursos. Tenía que auto-educarse para la composición de los diferentes tipos de ensayo, para la preparación ingeniosa de cartas de negocios, para la redacción de trabajos de fin de curso y, sobre todo, para la elaboración de la tesis de maestría o la disertación doctoral.

Las autoridades universitarias de ese entonces no estaban preparadas para concebir la idea de que se podía enseñar escritura a los jóvenes, mucho menos de que se les podía guiar para que pudieran crear y escribir historias verdaderas (nonfiction) o ficticias. Aunque el primer destello de que la escritura se podía enseñar sucedió en la Universidad de Iowa, en 1897, pero esa es otra historia.

Luego, algo ocurrió en el año de 1973. El profesor universitario James 
Gray, de la Universidad de Berkeley, estaba sorprendido y decepcionado porque casi la mitad de los estudiantes que habían sido admitidos por esa universidad y que fueron seleccionados por sus destacados conocimientos, tuvieron que tomar cursos remediales -sin valor curricular-, porque no tenían la menor idea de cómo redactar una simple nota. Pero no sólo eso, también se dio cuenta de que tampoco los profesores sabían comunicarse por escrito.

Se detectó que las habilidades escriturales de los estadounidenses iban en descenso, lo cual se percibía en las escuelas y en los sitios de trabajo, y esto, que se llamó “la crisis de la escritura” y que numerosos estudiosos habían señalado constantemente, prendió la alarma.

En ese entonces, Gray dijo "Cap (Lavin) y yo nos dimos cuenta de que todos los maestros de todos los niveles, salvo raras excepciones, no estaban entrenados para enseñar a escribir (ni escribían). Los de primaria enseñaban a leer, los de secundaria literatura inglesa... nadie había sido requerido a tomar un curso de enseñanza de escritura”.

Al mismo tiempo, Gray pensó que había que hacer algo con los educadores cuyos estudiantes fueron exitosos escritores académicos en esas evaluaciones, pues sus experiencias en la enseñanza, que podían beneficiar a otros compañeros, permanecían ocultas, anónimas, beneficiando solo a unos cuantos estudiantes y a ningún colega.

En 1974, Gray y su colega Cap crearon un programa denominado ‘instituto de verano’ (que más que un 'instituto’ fue una asociación voluntaria de maestros), a donde convocó a toda clase de profesores -desde maestros de kínder hasta profesores de universidad-, para rescatar sus experiencias y diseminarlas, creando, así, una denominada 'comunidad de aprendizaje'.

A esta iniciativa se le conoce como 'Programa de Escritura del Área de la Bahía' (Bay Area Writing Project, BAWP) en Berkeley University, pues congregó a maestros de esa zona. Durante 5 semanas trabajaron en su 'instituto de verano’, y cada participante dio una demostración de qué manera trabajaba con los estudiantes. En conjunto, los instructores analizaron toda clase de libros y artículos relevantes sobre el tema, y desarrollaron un curriculum sobre la enseñanza de la escritura; sobre todo, para enseñar a otros maestros a enseñar escritura en el aula, sin importar el nivel ni la disciplina.

Al parecer, esta fue la primera ocasión en ese país en que profesores de todos los niveles educativos se reunieron para colaborar en un proyecto común, y para escucharse sus experiencias entre sí.

Muchos esperaban que esto de 'maestros que enseñan a maestros' no fuese bien visto ni aceptado, pero la respuesta fue abrumadora. El proyecto comenzó a crecer y diseminarse por todo el país, y, entre 1976 y 1996, ya se habían entrenado a 84,969 maestros de todos los niveles y ámbitos educativos. Los centros de escritura comenzaron a multiplicarse por todo el país, en toda clase de escuelas, en todos los niveles educativos. 
Del proyecto de la Bahía emanó el denominado 'Programa Nacional de Escritura' (National Writing Project, NWP), que se convirtió en un semillero de maestros investigadores y promotores de la escritura, escritores publicados, conferencistas, líderes y docentes que enseñaban a escribir, reforzándose los unos a los otros, los cuales se esforzaron por transmitir sus conocimientos prácticos a otros.

Los maestros se capacitan y hacen labor de proselitismo para que otros conozcan el programa y participen. Además, el programa está bajo constante escrutinio y mejoría. Esta apertura es la que le ha dado permanencia hasta la actualidad.

Lejos de la idea fantasiosa de que los talleres de escritura son para formar novelistas o poetas (que esa idea es común en México, y esa si es la orientación de los MFA - Master in Fine Arts), la visión del NWP es totalmente pragmática. De acuerdo a MA Smith, algunas de las estrategias promovidas por el NWP que se ponen en práctica en los talleres de escritura, son que:

- Se presenta la escritura como un proceso. Se exhorta a los estudiantes a comportarse como escritores, a elegir sus temas, a planear y desarrollarlos, a investigarlos, a compartir y consultar con sus compañeros; a elaborar el borrador, revisarlo, editarlo y publicarlo en su mural o revista o blog.

- Se les alienta a escribir sobre diversos temas y que vayan más allá de los asuntos escolares; que trabajen géneros de toda clase (autobiografía, poesía, cuento, cartas de negocios, reportes, artículos, etc.), y se dirijan a otras audiencias diferentes de ellos mismos.

- Se les anima a utilizar la escritura como una forma de aprendizaje, utilizándola como herramienta para pensar con mayor claridad, para plantear y resolver problemas, para analizar pensamientos complejos.

- Se les promueve a identificarse a sí mismos como escritores, a ver a sus compañeros de la misma manera, y a conformar 'comunidades de escritores'.

En noviembre del 2005, James Gray falleció a los 78 años. El National Writing Project (NPW) que él fundó, siguió multiplicándose por todo el país, y en ese año tenía ya 189 proyectos de escritura establecidos en el mismo número de universidades

El espíritu del National Writing Project (NWP), en palabras de James Gray, se rige por lo siguiente:

"La escritura es esencial.

Escribir es esencial para la comunicación, el aprendizaje, el ejercicio de la ciudadanía.

Es la moneda de cambio de los nuevos sitios de trabajo y de la economía global.

La escritura nos ayuda a expresar nuestras ideas, a resolver problemas, y entender nuestro mundo cambiante.

La escritura es un puente hacia el futuro". 